\title{
INVESTIGATING CONSUMER BEHAVIOR IN ONLINE SHOPPING AMONG UNIVERSITY STUDENTS IN TWO COUNTRIES
}

\author{
DOI: 10.17261/Pressacademia.2020.1185 \\ RJBM-V.7-ISS.1-2020(3)-p.23-33
}

\author{
Abdulkadir Ozdemir ${ }^{1}$, Mohammad Naserinia² \\ ${ }^{1}$ Bandirma Onyedi Eylul University, Omer Seyfettin Applied Sciences Faculty, Bandirma, Balikesir, Turkey. \\ a.ozdemir@bandirma.edu.tr, ORCID: 0000-0002-7544-5579 \\ ${ }^{2}$ Ataturk University, Institute of Social Sciences, Erzurum, Turkey. \\ Naserinia.1986@gmail.com, ORCID:0000-0002-1681-440X
}

Date Received: January 6, 2020

Date Accepted: March 9, 2020

To cite this document

Ozdemir,A., Naserinia, M., (2020). Investigating consumer behavior in online shopping among university students in two countries. Research Journal of Business and Management (RJBM), V.7(1), p.23-33.

Permenant link to this document: http://doi.org/10.17261/Pressacademia.2020.1185

Copyright: Published by PressAcademia and limited licensed are-use rights only.

\section{ABSTRACT}

Purpose - The purpose of this study is to show how different countries, different cultures and technological infrastructures affect the behaviors of people via internet. In this study, the online shopping approach, which is part of e-commerce, has been studied among students from both countries. The technology aacceptance model was used to study the effective factors on student e-shopping behavior and this research is taken from the thesis defended in 2019.

Methodology - The data of thesis were collected from students at Ataturk University in Turkey and Tabriz University in Iran. Processing of collected data as well as proof of hypotheses have been made using the technology acceptance model.

Findings- Students' intention to accept online shopping technology has a significant impact on their actual behavior, which is $71.7 \%$ among students at the University of Ataturk and $67.6 \%$ among students of Tabriz University.

Conclusion- According to the results, it is seen that there is a significant proportion of both university students' intention and attitude about eshopping. In addition, it has been observed that the technological infrastructure and usage periods have a positive effect on e-shopping.

Keywords: E-commerce, online shopping, technology acceptance model. JEL Codes: P13, N85, N95

\section{INTRODUCTION}

In the late 1980s, the world was on the verge of a technological revolution after the first industrial revolution in the mid-19th century with the advent of steam in the textile and telecommunications industry. The second revolution happened with the introduction of electricity in industrialized and consumer markets in developed countries. The Third Revolution was based on the rapid expansion of ICTs and their continuous improvement with increasing efficiency and rapid cost reductions. Since then, these technologies have spread rapidly in developed countries and in developing countries. Today's businesses have focused information technology as an integral part of their activities in order to compete in global markets (Oliveira et al., 2014). Also, shopping has become an inevitable aspect of one's life because human needs are inevitable and this can be done either in traditional or retail or online shopping. Both traditional and online shopping have different advantages, but e-shopping is still a focus for users due to their time saving. People use tools like laptops, tablets, and cell phones to shop online. Online shopping generally gives sellers and shoppers a shared platform (mobile applications or websites) to exchange goods and services at a price (Kumar et al., 2016). Online shopping offers consumers the opportunity to shop online anytime and anywhere through various payment methods such as debit cards, credit cards, gift cards, cash on delivery, bank transfer, mobile money (Johnson, 2015). $n$ this regard, not only developed countries but also developing countries have also benefited from the development of ICT (Patel 
and Patel, 2018). The new generation, especially those with higher education, are usually exposed to technology, so they use the Internet regularly in their daily activities. As a result, they tend to shop online than other older people (Mandhlazi et al., 2013).

The most dominant theory used to understand the behavior of consumers or users of technology is the Technology Acceptance Model (TAM) by (Davis, 1989). The technology acceptance model (TAM) has been the subject of much interest in the literature (Davis, 1989). Because the Technology Acceptance Model (TAM) is a social-cognitive paradigm in the study of human behavior in technology (Venkatesh and Bala, 2008) that determines the extent of user acceptance and use of new technology. Many researchers have attempted to enrich basic TAM and explain user acceptance of technologies using other more precise variables (Ingham et al., 2015). Others have applied TAM to specific technology areas, such as e-commerce or online shopping, and have proposed other components for the user acceptance model (Agrebi and Jallais, 2015). TAM has been used in various behavioral studies in information and communication technology (ICT and systems), health care systems, enterprise resource planning systems, mobile banking technology, internet and commerce (Amirtha and Sivakumar, 2018).

The development of e-commerce depends on the consumer acceptance of the use of internet technologies. When using new technologies such as the web and e-commerce, consumer trust is important. Trust is usually one of the factors that have an important role in online purchases (Singh et al., 2016). Although e-commerce has been known as the sale of products and services on the Internet in recent years, it is still a new concept for many people. Therefore, it is important to find ways to encourage consumers to continuously use e-commerce (Oliveira et al., 2017). In the online shopping process, which is part of e-commerce, consumers use the internet to search for information when they need some goods or services (Javadi et al., 2012). Electronic shoppers benefit from time saving and can buy at any time. Therefore, they can shop at home without going to traditional stores (Jiang et al., 2013). Even if they are away from stores, they can easily make their purchases (Richa, 2012).

The purpose of this study is to show how different countries, different cultures and technological infrastructures affect the behaviors of people via internet. In this study, various impacts of factors such as Trust, Facilitating Conditions, Enjoyment, Perceived Usefulness, Perceives Ease of Use and Attitude on the actual behavior of users are considered.

In this paper, Section 2 deals with the literature review, then in Section Three, we define the variables and their relationship. The method is discussed in section four and the findings in section five. Finally, in section six, it is about conclusions.

\section{LITERATURE REVIEW}

The model was used in this study is TAM (Technology Acceptance Model) (Davis, 1986). It presents the conceptual framework for our study. Davis (1986) has introduced TAM that has been used to explain the behavior of users and examine the use of information technology (Çelik and Yılmaz, 2011). TAM is actually a model used by researchers to study the behavior of information systems (Fayad and Paper, 2015).

Yoon (2009) investigated the effect of national culture on the acceptance of e-commerce by consumer in China. Data were collected from university students in China. Questionnaires were distributed among 270 students in China. About 80 percent of the participants have had an internet shopping experience for more than 3 years, and only 10 percent have an internet shopping experience by shopping more than once a month. The results showed that national cultural values affect the acceptance of ecommerce users, and avoiding uncertainty and long-term orientation has a significant impact on the relationship between trust and intent.

Oni and Ayo (2010) investigate the factors that determine the behavioral intention of users in determining the level of accepting electronic banking services and using electronic banking systems in Nigeria. The Technology Acceptance Model (TAM) was used to investigate the factors affecting the acceptance and intention of electronic banking users. Data were collected from 292 customers from various commercial banks in Nigeria. The result of this study shows that ATM is still the most widely used form in e-Banking. In addition, the security of the system in terms of network security and privacy are the most important concern for users and the users are curious about this issue.

Park et al. (2012) study the use of mobile learning by university students. 288 students from Konkuk University were selected for the study. Research is based on technology acceptance model. He confirmed the acceptability of the model to explain that students accepted mobile learning. As a result of the study, the majority of students played an important role in affecting the mobile learning attitude and perceived benefit. Alraja and Aref (2015) studied the adoption of e-commerce by customers in their study. In this study, customer attitudes are targeted in Oman's electronic commerce. According to the results of the study, they prefer traditional purchases and e-commerce expertise are low. The number of e-commerce companies is still very small 
compared to the number of consumers. The perceived risk and perceived ease of use should be considered in the acceptance of e-commerce in the Sultanate of Oman.

Li et al. (2017) concluded that electronic auctions could increase the share of C2C markets by increasing the participation of current users. The purpose of this study was to investigate the factors influencing attitudes about electronic auctions among Chinese electronic users. Data were collected from 210 current users of electronic auctions in China. Using structural equation modeling, the results show that factors such as security, social incentives, fun, interactivity, creating a safe space, and being playful are important. Also, the speed of connection and economy and cost-effectiveness are key factors.

Weng et al. (2018) conducted a study "A TAM-based study of the attitude towards use intention of multimedia among school teachers". They believe that multimedia teaching materials are widely used in various disciplines. These resources provide teachers with an opportunity to share educational resources with students. This study uses the Technology Acceptance Model (TAM) as the primary model to examine the impacts of the IT environment on perceived usefulness, perceived ease, and attitude on behavior. Data were collected from 460 teachers using stratified random sampling. The results show that the ease of use of multimedia materials increases the intention to use. Also, attitude has a direct impact on intentions of use.

Ahmad et al. (2019) have examined the impact of electronic service quality on the actual use of electronic banking. Data were collected from 493 e-banking users in Pakistan and analyzed using AMOS 20 and SPSS 20 software. The results indicate that the quality of electronic services has a positive effect on perceived usefulness, perceived ease of use, and intention to use e-banking and perceived usefulness. Attitude also has a positive effect on the intention to use e-services and perceived ease affects attitude toward e-banking. The successive intermediation of attitude and intention between e-service quality and actual use of e-banking has been confirmed. This study is of great importance to banking industry executives, enabling them to influence the attitude of customers towards their services as well as helping them design strategies to improve their profitability.

Suleman et al. (2019) conducted a study "Decision Model Based on Technology Acceptance Model (Tam) for Online Shop Consumers in Indonesia". examine the relationship between usefulness, ease of use, and confidence in attitudes and purchasing decisions for fashion products online. Data were collected from 150 individuals with e-shopping experience. The results indicated that the usefulness, ease of use and influence of trust have a positive effect on attitude but self-esteem does not seem to affect consumer attitudes in online shopping. Also, a variable that influences attitudes is consumer confidence in online stores.

Singh and Srivastava (2019) conducted a study that aims to apply the technology acceptence model (TAM) capability to explain the widespread acceptance and use of social media (SM) for travel purposes by overseas travelers during their travels. The study used a qualitative approach and in-depth interviews of 30 respondents. This information has been carried out over the past 12 months. The findings of this study are used to develop a conceptual model that supports the validity of TAM with perceived usefulness and perceived ease (PEU) as determinants of SM use. This model is extended to perceived trust (PT) and social capital (SC) as important constructs to explain travelers' use of SM. User Disposal Preparedness (DR) of the user affected SM on all four constructs.

Granić and Marangunić (2019) conducted a study "Technology acceptance model in educational context: A systematic literature review". The main purpose of this review is to provide an overview of the current state of research efforts regarding the use of TAM in the field of learning and teaching for a variety of learning areas, learning technologies and types of users. Through systematic searches using the EBSCO Discovery Service, the survey identified 71 related studies between 2003 and 2018 . The main findings indicate that TAM and many of its different versions represent a valid model to facilitate the evaluation of diverse learning technologies. The results of this systematic review provide a better understanding of TAM acceptance studies in the field of education and provide a solid foundation for knowledge advancement in the field.

\section{TECHNOLOGY ACCEPTANCE MODEL AND HYPOTHESIS}

\subsection{Trust (T)}

The trust of people depends on buying methods. Consumers are very trusted in purchasing from the store because the level of risk of such purchases is low, but in online shopping, due to high risk and lack of security, people are less trusted. For this reason, trust in online shopping is an essential element (Al-Ajam and Nor, 2013). When interactions are not face to face, we need to win the trust of the people (Belanche et al, 2012; Harris and Goode, 2004). In the short term as well as in the long run, trust in electronic purchases increases the perceived benefits (Çelik and Yilmaz, 2011; Wang and Head, 2007). Therefore:

H1: Trust in e-shopping has a positive impact on the perception of the user in the usefulness of technology acceptance. 
$\mathrm{H} 2$ : Trust in e-shopping has a positive impact on the perception of the user in the use of ease in technology acceptance.

\subsection{Facilitating Conditions (FC)}

Venkatesh et al. (2003) defined Facilitating Conditions as "the degree to which an individual believes that an organizational and technical infrastructure exists to support the use of the system" (Mahadeo, 2009). In other words, facilitating conditions to elements of the environment that affect the person's desire to do something (Teo, 2010; Teo, 2012). The existence of facilitator conditions has a positive effect on perceived ease of use (Ngai et al., 2007). Therefore:

H3: The facilitating conditions provided by electronic purchases have a positive effect on the user's perception of usefulness.

H4: The facilitating conditions provided by electronic purchases have a positive effect on the user's perception in ease of use.

\subsection{Enjoyment (E)}

Enjoyment is in fact the intrinsic motive of the individual, which encourages users to use a new system or technology (Praveena and Thomas, 2014; Venkatesh, 2012). Therefore, one of the reasons for online shopping is the enjoyment factor (Cheema et al., 2013) because it has a significant impact on the customer's intent (Ha and Stoel, 2009, Wang and Goh, 2017) and encourages them to buy online (Thong et al., 2006). Online sellers should also pay attention to this factor (Cheema et al., 2013). Because the element of enjoyment, in addition to its impact on attitude, has a direct impact on perceived usefulness and perceived ease of use, and one of the backgrounds of these two factors is also considered (Abdullah and Ward, 2016). Even research Hsiao and Yang (2011) has shown that enjoyment is one of the key elements in TAM research. Therefore:

H5. The enjoyment of e-shopping has a positive effect on the user's perception of usefulness to accept technology.

H6. The enjoyment of e-shopping positively affects the user's perceived ease of use to accept technology.

\subsection{Perceived Usefulness (PU) and Perceives Ease of Use (PEU)}

Perceived Ease of Use (PEOU) is defined as the "degree to which the user expects the target system to be free of efforts (Davis, 1989)". In other words, one's understanding of new technology or online sites is such that their use is easy and does not require much effort, which in turn affects the perceived usefulness of it. In fact, Perceived Ease of Use has a positive impact on the perceived of usefulness (Teo, 2010; Teo, 2012). Most people's point of view on technology or online sites is that they are complex, but if customers understand that their use is easy, then they will have a positive attitude, which in turn will have a positive and direct impact on customer attitude (Pando-Garcia et al., 2016).

Perceived usefulness means that the customer understands that buying online or using a new system will increase performance and efficiency (Chang and Tung, 2008; Lee, 2006). Perceived usefulness is considered as an influential factor in attitudes and is more common in private organizations, including online shopping companies (Wang and Tseng, 2011). Perceived usefulness, in addition to having a direct impact on consumer attitude (Hanafizadeh et al., 2014), also encourages the customer to buy online (Barkhi and Wallace, 2007). Therefore:

H7: Perceived ease of use in e-shopping has a direct relationship with perceived the usefulness of technology acceptance.

H8: Perceived the usefulness of technology in e-shopping has a positive impact on their attitude.

H9: Perceived the ease of use in e-shopping has a positive impact on their attitude.

\subsection{Attitude (A), Intention (I) and Actual Behavior (AB)}

Attitude is defined as "the degree to which a person has a favourable or unfavourable evaluation or appraisal of the behavior in question" (Ajzen, 1991). Attitude is considered as the background of intentions (Suki and Ramayah, 2010). Researchers have highlighted the expectations of users and their feelings about using websites (Chen et al., 2004; Suh and Han, 2002). Obviously, whatever the consumer's attitude to online shopping is positive, their intention to buy online is also increasing (Ahn et al., 2004). On the other hand, the actual behavior shows the extent to which a technology is used (Sánchez-Prieto et al., 2017). The higher the intentions of people to shop online, the more real people's behavior will increase. Therefore:

H10: Users' attitude towards e-shopping positively affects their intention to accept this technology.

H11: Users' intention to accept e-shopping positively affects their actual behavior. 
Figure 1: Hypotheses and Their Relations in the Model

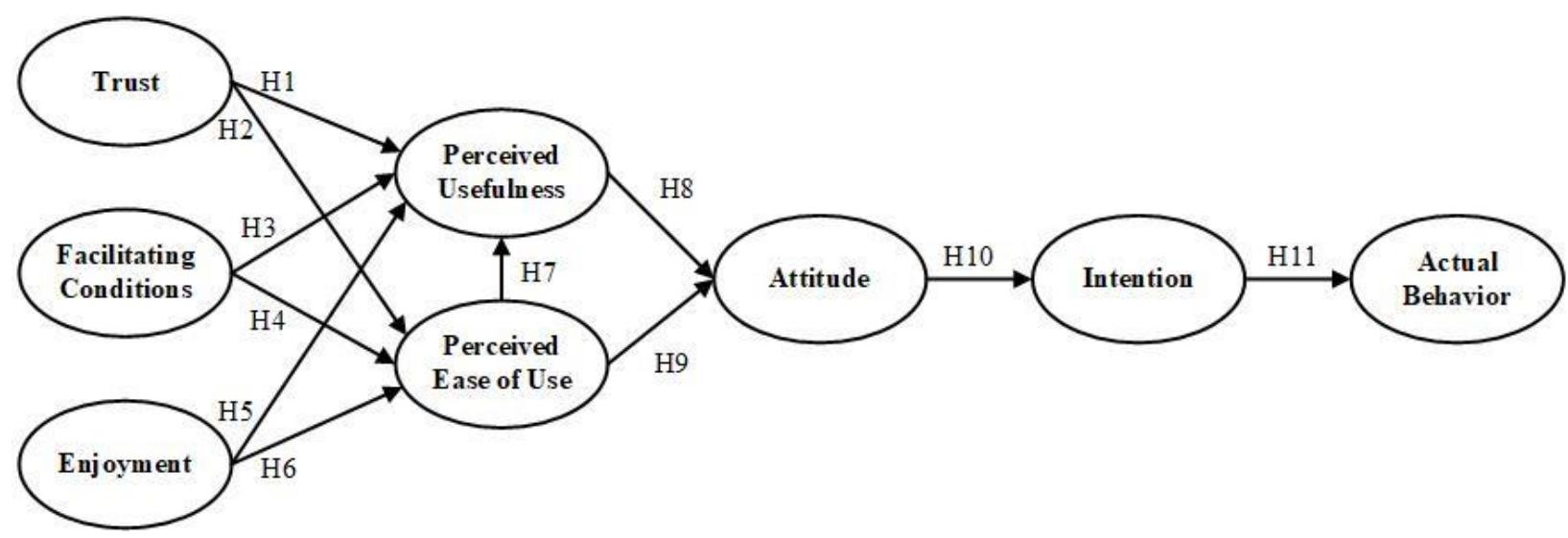

\section{METHODOLOGY}

The aim of this study was to investigate the attitudes and behaviors of the students towards e-shopping at Ataturk University and Tabriz University. 420 students from Ataturk University and 415 students from Tabriz University were selected to determine their attitudes, behaviors and characteristics. Also, the questionnaire included 40 questions. 27 of the 420 questionnaires at Ataturk University were excluded due to their deficiencies and a total of 393 questionnaires were evaluated. In Tabriz University, 19 of 415 questionnaires were removed and a total of 396 questionnaires were collected (data from a master's thesis entitled "The study of the purchase of university students in different cultures through the adoption of online technology in the Institute of Systems Ataturk University of Social Sciences Information").

The SPSS 24.0 program was used to evaluate the data and then the structural equation model was created with AMOS 24.0 program. The regression analyses and data analysis of the hypotheses were done with this model. The Cronbach's Alpha value of the study was 0.947 for Ataturk University and 0.934 for Tabriz University. According to this, the Cronbach's Alpha value of Ataturk University was slightly higher than the Cronbach's Alpha of Tabriz University, but both showed a high degree of reliability.

\section{FINDINGS}

Data analysis of two universities related to demographic questions is given in the table below. It can be seen from the table, 222 of the students participating in the survey at Ataturk University are women and 171 male students. Those who used Internet for more than 5 hours were 35.6 percent, and those who had already made online shopping were 82.7 percent. The surveyed students in the University of Tabriz are 209 female and 187 male. $34.6 \%$ of the participants used the Internet for more than 5 hours, and $80.1 \%$ had previously had electronic purchases.

Table 1: information of Surveyed Students

\begin{tabular}{|l|l|c|c|c|c|}
\cline { 3 - 6 } \multicolumn{2}{c|}{} & \multicolumn{2}{c|}{ Ataturk University } & \multicolumn{2}{c|}{ Tabriz University } \\
\hline \multirow{3}{*}{ Gender } & Variable & Frequency & Percent \% & Frequency & Percent \% \\
\hline \multirow{3}{*}{\begin{tabular}{l} 
Level of education \\
\cline { 2 - 6 }
\end{tabular}} & Woman & 222 & 56,5 & 209 & 52,8 \\
\cline { 2 - 6 } & Male & 171 & 43,5 & 187 & 47,2 \\
\cline { 2 - 6 } & Associate & 33 & 8,4 & 7 & 1,8 \\
\cline { 2 - 6 } & License & 302 & 76,8 & 291 & 73,5 \\
\cline { 2 - 6 } & Master's Degree & 41 & 10,4 & 87 & 22,0 \\
\cline { 2 - 6 } & Doctorate & 210 & 5,3 & 11 & 2,8 \\
\hline \multirow{2}{*}{$\begin{array}{l}\text { Minimum daily use of the } \\
\text { computer }\end{array}$} & Less than 2 hours & 70 & 17,4 & 186 & 47,0 \\
\cline { 2 - 6 } & $2-3$ hours & & & 21,2 \\
\hline
\end{tabular}




\begin{tabular}{|c|c|c|c|c|c|}
\hline & 3-4 hours & 38 & 9,7 & 52 & 13,1 \\
\hline & 4-5 hours & 23 & 5,9 & 26 & 6,6 \\
\hline & More than 5 hours & 52 & 13,2 & 48 & 12,1 \\
\hline \multirow{5}{*}{$\begin{array}{l}\text { Minimum daily use of the } \\
\text { internet }\end{array}$} & Less than 2 hours & 42 & 10,7 & 42 & 10,6 \\
\hline & $2-3$ hours & 79 & 20,1 & 66 & 16,07 \\
\hline & 3-4 hours & 72 & 18,3 & 79 & 19,9 \\
\hline & 4-5 hours & 60 & 15,3 & 72 & 18,2 \\
\hline & More than 5 hours & 140 & 35,6 & 137 & 34,6 \\
\hline \multirow{6}{*}{$\begin{array}{l}\text { Monthly average income } \\
\text { (how much TL) }\end{array}$} & Less than 500 & 206 & 52,4 & 276 & 69,7 \\
\hline & $500-7500$ & 86 & 21,9 & 69 & 17,4 \\
\hline & $751-1.000$ & 34 & 8,7 & 19 & 4,8 \\
\hline & $1.001-1.250$ & 12 & 3,1 & 14 & 3,5 \\
\hline & $1.251-1.500$ & 7 & 1,8 & 4 & 1,0 \\
\hline & More than 1500 & 48 & 12,2 & 14 & 3,5 \\
\hline \multirow[t]{2}{*}{ Previous E-shopping } & Yes & 325 & 82,7 & 317 & 80,1 \\
\hline & No & 68 & 17.3 & 79 & 19,9 \\
\hline
\end{tabular}

The compliance measures of Ataturk University and Tabriz University model are shown in the table below. The data of both models were considered for the suitability of the factors.

Table 2: Adaptation Values of Ataturk University Structural Model

\begin{tabular}{|l|l|l|l|}
\hline Fit Measure & Ideal Compliance Values & Acceptable Compliance Values & Compliance Value of Factor \\
\hline$\chi 2$ & $(\mathrm{P}>0,05)$ It is desirable. & & 643,426 \\
\hline$\chi 2 / \mathrm{df}$ & $\chi 2 / \mathrm{df} \leq 2$ & $\chi 2 / \mathrm{df} \leq 5$ & 1,716 \\
\hline $\mathrm{RMSEA}$ & $0.00<\mathrm{RMSEA}<0.05$ & $0.05<\mathrm{RMSEA}<0.10$ & 0,043 \\
\hline $\mathrm{GFI}$ & $0.95<\mathrm{GFI}<1.00$ & $0.90<\mathrm{GFI}<0.95$ & 0,901 \\
\hline $\mathrm{AGFI}$ & $0.90<\mathrm{AGFI}<1.00$ & $0.80<\mathrm{AGFI}<0.90$ & 0,877 \\
\hline $\mathrm{CFI}$ & $0.95<\mathrm{CFI}<1.00$ & $0.90<\mathrm{CFI}<0.95$ & 0,959 \\
\hline $\mathrm{NFI}$ & $0.95<\mathrm{NFI}<1.00$ & $0.90 \leq \mathrm{NFI}<0.95$ & 0,909 \\
\hline $\mathrm{TLI}$ & $0.95<\mathrm{TLI}<1.00$ & $0.90 \leq \mathrm{NFI}<0.95$ & 0,953 \\
\hline $\mathrm{RFI}$ & $0.90<\mathrm{RFI}<1.00$ & $0.85<\mathrm{RFI}<0.90$ & 0,894 \\
\hline
\end{tabular}

Table 3: Adaptation Values of Tabriz University Structural Model

\begin{tabular}{|l|l|l|l|}
\hline Fit Measure & Ideal Compliance Values & Acceptable Compliance Values & Compliance Value of Factor \\
\hline$\chi 2$ & $(\mathrm{P}>0,05)$ It is desirable. & & 525,036 \\
\hline$\chi 2 / \mathrm{df}$ & $\chi 2 / \mathrm{df} \leq 2$ & $\chi 2 / \mathrm{df} \leq 5$ & 1,415 \\
\hline $\mathrm{RMSEA}$ & $0.00<\mathrm{RMSEA}<0.05$ & $0.05<\mathrm{RMSEA}<0.10$ & $0 ., 032$ \\
\hline $\mathrm{GFI}$ & $0.95<\mathrm{GFI}<1.00$ & $0.90<\mathrm{GFI}<0.95$ & 0,920 \\
\hline $\mathrm{AGFI}$ & $0.90<\mathrm{AGFI}<1.00$ & $0.80<\mathrm{AGFI}<0.90$ & 0,900 \\
\hline $\mathrm{CFI}$ & $0.95<\mathrm{CFI}<1.00$ & $0.90<\mathrm{CFI}<0.95$ & 0,968 \\
\hline $\mathrm{NFI}$ & $0.95<\mathrm{NFI}<1.00$ & $0.90 \leq \mathrm{NFI}<0.95$ & 0,901 \\
\hline TLI & $0.95<\mathrm{TLI}<1.00$ & $0.90 \leq \mathrm{NFI}<0.95$ & 0,963 \\
\hline $\mathrm{RFI}$ & $0.90<\mathrm{RFI}<1.00$ & $0.85<\mathrm{RFI}<0.90$ & 0,884 \\
\hline
\end{tabular}

It can be said that the ideal $\chi 2$ ratio $(\chi 2 / d f=643,426 / 375)$ is 1.716 in the model of Ataturk University and according to this result $(\chi 2 / d f \leq 5)$ it is the ideal adaptation. Since the $\chi 2$ ratio $(\chi 2 / d f=525,036 / 371)$ in the University of Tabriz is 1.415 , it can be said that this is an ideal fit for this place $(\chi 2 / d f \leq 5)$. In addition, the RMSEA value at Ataturk University is 0.043 and RMSEA value is 0.032 at Tabriz University. As the GFI value was 0.901 in Ataturk University model and the GFI value in Tabriz University model was 0.920 , the model is considered acceptable. In addition, the model of the University of Ataturk with an AGFI of 0.877 and the model of Tabriz University with a AGFI of 0.900 are acceptable. The value of CFI seems to be an ideal fit value since it is 0.959 in 
Ataturk University and 0.968 in Tabriz University. NFI value is calculated as 0.909 in Ataturk University model and 0.901 in Tabriz University and these values are considered to be ideal. The TLI values of the models were found to be 0,953 in Ataturk University and 0,963 in Tabriz University. Finally, RFI values are calculated as 0,894 in Ataturk University model and 0,884 in Tabriz University model, and these values are accepted.

Table 4: The Regression Loads and Hypotheses of the Two Models

\begin{tabular}{|c|c|c|c|c|c|c|}
\hline \multirow[b]{2}{*}{ Structural Relations in the Model } & \multicolumn{3}{|c|}{ Ataturk University } & \multicolumn{3}{|c|}{ Tabriz University } \\
\hline & $\begin{array}{l}\text { Regression } \\
\text { Loads }\end{array}$ & P Value & $\begin{array}{l}\text { Hypothesi } \\
\text { s Result }\end{array}$ & $\begin{array}{l}\text { Regression } \\
\text { Loads }\end{array}$ & P Value & $\begin{array}{l}\text { Hypothesis } \\
\text { Result }\end{array}$ \\
\hline \multicolumn{7}{|c|}{ Variables Affecting Perceived Usefulness (PU) Factor } \\
\hline H1:PU---TRUST & 0.183 & 0.000 & ACCEPT & 0.190 & 0.000 & ACCEPT \\
\hline H3:PU---FACILATING CONDITIONS & 0.256 & 0.000 & ACCEPT & 0.010 & 0.895 & REJECT \\
\hline H5:PU---ENJOYMENT & 0.270 & 0.000 & ACCEPT & 0.404 & 0.000 & ACCEPT \\
\hline H7:PU---PEU & 0.425 & 0.000 & ACCEPT & 0.532 & 0.000 & ACCEPT \\
\hline \multicolumn{7}{|c|}{ Variables Affecting Perceived Ease of Use (PEU)Factor } \\
\hline H2:PEU---TRUST & -0.041 & 0.519 & REJECT & 0.038 & 0.609 & REJECT \\
\hline $\begin{array}{l}\text { H4:PEU---FACILATING } \\
\text { CONDITIONS }\end{array}$ & 0.669 & 0.000 & ACCEPT & 0.681 & 0.000 & ACCEPT \\
\hline H6:PEU--- ENJOYMENT & 0.118 & 0.065 & REJECT & 0.158 & 0.070 & REJECT \\
\hline \multicolumn{7}{|c|}{ Variables Affecting Attitude Factor } \\
\hline H8:ATTITUDE---PU & 0.921 & 0.000 & ACCEPT & 0.943 & 0.000 & ACCEPT \\
\hline H9: ATTITUDE ---PEU & -0.019 & -0.071 & REJECT & -0.193 & 0.056 & REJECT \\
\hline \multicolumn{7}{|l|}{ Variables Affecting Intent Factor } \\
\hline H10: INTENTION--- ATTITUDE & 0.939 & 0.000 & ACCEPT & 0.975 & 0.000 & ACCEPT \\
\hline \multicolumn{7}{|l|}{ Variables affecting actual behavior } \\
\hline $\begin{array}{l}\text { H11:ACTUAL BEHAVIOR--- } \\
\text { INTENTION }\end{array}$ & 0.717 & 0.000 & ACCEPT & 0.676 & 0.000 & ACCEPT \\
\hline
\end{tabular}

The trust variable positively affects the perceived usefulness factor (Ataturk University regression load $=0,183 ; p=000<0,05 ;$ and Tabriz University regression load $=0,190 ; p=000<0,05)$. Therefore, it is seen that e-shopping is safe and useful in their lives and $\mathrm{H} 1$ hypothesis is accepted.

At Ataturk University model, the facilitator conditions positively affect the perceived usefulness factor ( regression load = $0.256 ; \mathrm{p}$ $=000<0.05$ ). From the viewpoint of the students, the facilitator's service in online shopping for the user is an indicator of perceived usefulness, and therefore hypothesis 3 is accepted. However, in the Tabriz University model, the Facilitator conditions variable has a negative effect on the perceived usefulness factor (Regression load $=0.010$ ), in other words, the hypothesis $\mathrm{H} 3$ was rejected in Tabriz University, unlike Ataturk University, because of its $P$ value of 0.895 and greater than 0.05 . The enjoyment variable has a positive effect on the perceived usefulness factor. Ataturk University Regression Load $=0,270 ; p=000<0.05$ and Tabriz University Regression load $=0.681$; Since $p=000<0.05$, the benefit of shopping for students shows that they think e-shopping is usefulness in their lives. H5 hypothesis was accepted. Furthermore, perceived ease of use positively affects the perceived usefulness factor. Ataturk University Regression Load $=0,425 ; p=000<0.05$ and Tabriz University Regression load $=0.532$; Since $\mathrm{p}=000<0.05$, the students think that it will be useful for easy e-shopping and $\mathrm{H} 7$ is accepted.

The trust variable has a negative effect on the perceived ease of use factor. Regression load of Ataturk University $=-0,041$ and Regression load of Tabriz University $=0,038$. In other words, the $\mathrm{H} 2$ hypothesis was rejected because the $\mathrm{P}$ value was greater than 
0.05 with a value of 0.529 . The facilitating conditions variable positively affects the perceived ease of use factor. Regression load of Ataturk University $=-0,041$ and Regression load of Tabriz University $=0,038$. In other words, the $\mathrm{H} 2$ hypothesis was rejected because the $P$ value was greater than 0.05 with a value of 0.529 . The facilitating conditions variable positively affects the perceived ease of use factor. Ataturk University Regression Load = 0,669; $p=000<0.05$ and Tabriz University Regression load $=$ 0.681; Since $p=000<0.05$, the facilitator shopping services that are on e-shopping for the students show their perception of ease of use. $\mathrm{H} 4$ hypothesis was accepted. The enjoyment variable adversely affects the perceived ease of use factor. Ataturk University Regression Load $=0.425$ and University of Tabriz Regression Load $=0,158$, hypothesis 6 was rejected because the value of $p$ is 0.065 and this value is greater than 0.05 .

From the variables that affect the attitude factor, the perceived usefulness variable affects the attitude factor positively. Ataturk University Regression Load $=0.921 ; p=000<0.05$ and Tabriz University Regression load $=0.943$; Since $p=000<0.05$, students perceive e-exchanges as usefulness and positively affect their attitudes towards their use and hypothesis $\mathrm{H} 8$ is accepted. In addition, the perceived ease of use factor had a negative effect on attitude, and Ataturk University's regression load was found to be -0.019 and Tabriz University regression load was $=-0.191$. Because $\mathrm{P}$ value was 0.071 and greater than 0.05 , H9 hypothesis was rejected.

The attitude variable has a positive effect on the intention factor. Ataturk University Regression Load $=0,939 ; p=000<0.05$ and Tabriz University Regression load $=0.975$; Since $p=000<0.05$, the students' e-shopping attitudes are positive, so they indicate their intention to do so and therefore the $\mathrm{H} 10$ hypothesis is accepted. Finally, the variable of intent affects the behavior factor positively. Ataturk University Regression Load $=0.717 ; p=000<0.05$ and Tabriz University Regression load $=0.676 ; p=000<0.05$ is the intention of the students to e-shopping, this intention is directed to the behavior and $\mathrm{H} 11$ hypothesis is accepted.

\section{CONCLUSION}

While $56.5 \%$ of the students participating in the survey from Ataturk University were women and $73.5 \%$ were men, $52.8 \%$ of the students in Tabriz University were women and $47.2 \%$ men. It is observed that the majority of both university students is formed by undergraduate education. Most Ataturk University students use computers less than 2 hours a day, while Tabriz University students use computers for more than 2 hours, but the rate of Internet use for students of Tabriz University is similar to those of Ataturk University. Increasing users' trust increases the perceived usefulness of this percentage among students at Ataturk University $18.3 \%$ and Tabriz University $19 \%$.

Regarding the trust variable, it can be said that they do not perceive the ease of use of e-shopping in both universities because they are unstable. Facilitating conditions increased the perceived usefulness among Ataturk University students, which is 25.6 percent, while facilitating conditions had no effect on the perceived usefulness of students at Tabriz University because they were unstable. In addition, facilitator conditions have increased the perceived ease of use, which is $66.9 \%$ at Ataturk University and 68.1 in Tabriz University. The increase in the enjoyment of users increases the perceived usefulness of Ataturk University by $27 \%$ and the University of Tabriz by $40.1 \%$. They also do not perceive ease of use because they are unstable at both universities. They also do not perceive ease of use because they are unstable at both universities. The increase in users' perceived ease of use increases the perceived usefulness of Ataturk University by $42.5 \%$ and Tabriz University by $53.2 \%$. Users' perceived ease of use does not affect their attitude as they are unstable in both universities. The increase in the attitudes of the users increased their intentions by $93.9 \%$ in Ataturk University and $97.5 \%$ in Tabriz University. The most important thing is that the increase in the intentions of the users increases by $71.7 \%$ in Ataturk University and $67.6 \%$ in the Tabriz University. According to these results, it is seen that there is a significant proportion of both university students' intention and attitude about e-shopping. In addition, it has been observed that the technological infrastructure and usage periods have a positive effect on e-shopping.

According to the model of both universities, because the effect of trust on perceived usefulness is low, it is less perceived as beneficial for students because e-shopping is less secure. On the other hand, in both universities, the perceived usefulness has a high impact on the attitude, so it is more influential on the attitudes of the students to make the e-shopping so useful.

\section{REFERENCES}

Abdullah, F., \& Ward, R. (2016). Developing a General Extended Technology Acceptance Model for E-Learning (GETAMEL) by analysing commonly used external factors. Computers in Human Behavior, 56, 238-256.

Agrebi, S., \& Jallais, J. (2015). Explain the intention to use smartphones for mobile shopping. Journal of retailing and consumer services, $22,16-23$. 
Ahmad, S., Bhatti, S. H., \& Hwang, Y. (2019). E-service quality and actual use of e-banking: Explanation through the Technology Acceptance Model. Information Development, 0266666919871611.

Ahn, T., Ryu, S., \& Han, I. (2004). The impact of the online and offline features on the user acceptance of Internet shopping malls. Electronic Commerce Research and Applications, 3(4), 405-420.

Ajzen, I. (1991). The theory of planned behavior. Organizational behavior and human decision processes, 50(2), 179-211.

Al-Ajam, A. S., \& Nor, K. M. (2013). Internet banking adoption: integrating technology acceptance model and trust. European Journal of Business and Management, 5(3), 207-215.

ALraja, M. N., \& Aref, M. (2015). Customer acceptance of e-commerce: Integrating perceived risk with TAM. International Journal of Applied Business and Economic Research, 13(2), 913-921.

Amirtha, R., \& Sivakumar, V. J. (2018). Does family life cycle stage influence e-shopping acceptance by Indian women? An examination using the technology acceptance model. Behaviour \& Information Technology, 37(3), 267-294.

Barkhi, R., \& Wallace, L. (2007). The impact of personality type on purchasing decisions in virtual stores. Information Technology and Management, 8(4), 313-330.

Belanche, D., Casaló, L. V., \& Flavián, C. (2012). Integrating trust and personal values into the Technology Acceptance Model: The case of egovernment services adoption. Cuadernos de Economía y Dirección de la Empresa, 15(4), 192-204.

Çelik, H. E., \& Yilmaz, V. (2011). Extending the technology acceptance model for adoption of e-shopping by consumers in Turkey. Journal of Electronic Commerce Research, 12(2), 152.

Chang, S. C., \& Tung, F. C. (2008). An empirical investigation of students' behavioural intentions to use the online learning course websites. British Journal of Educational Technology, 39(1), 71-83.

Cheema, U., Rizwan, M., Jalal, R., Durrani, F., \& Sohail, N. (2013). The trend of online shopping in 21st century: Impact of enjoyment in TAM Model. Asian Journal of Empirical Research, 3(2), 131-141.

Chen, L. D., Gillenson, M. L., \& Sherrell, D. L. (2004). Consumer acceptance of virtual stores: A theoretical model and critical success factors for virtual stores. ACM Sigmis Database, 35(2), 8-31.

Davis, F. D. (1989). Perceived usefulness, perceived ease of use, and user acceptance of information technology. MIS quarterly, $319-340$.

Davis, F. D. (1989). Perceived usefulness, perceived ease of use, and user acceptance of information technology. MIS quarterly, 319-340.

Fayad, R., \& Paper, D. (2015). The technology acceptance model e-commerce extension: a conceptual framework. Procedia Economics and Finance, 26, 1000-1006.

Granić, A., \& Marangunić, N. (2019). Technology acceptance model in educational context: A systematic literature review. British Journal of Educational Technology, 50(5), 2572-2593.

Ha, S., \& Stoel, L. (2009). Consumer e-shopping acceptance: Antecedents in a technology acceptance model. Journal of business research, 62(5), 565-571.

Hanafizadeh, P., Behboudi, M., Koshksaray, A. A., \& Tabar, M. J. S. (2014). Mobile-banking adoption by Iranian bank clients. Telematics and Informatics, 31(1), 62-78.

Harris, L. C., \& Goode, M. M. (2004). The four levels of loyalty and the pivotal role of trust: a study of online service dynamics. Journal of retailing, 80(2), 139-158.

Hsiao, C. H., \& Yang, C. (2011). The intellectual development of the technology acceptance model: A co-citation analysis. International Journal of Information Management, 31(2), 128-136.

Ingham, J., Cadieux, J., \& Berrada, A. M. (2015). e-Shopping acceptance: A qualitative and meta-analytic review. Information \& Management, 52(1), 44-60.

Javadi, M. H. M., Dolatabadi, H. R., Nourbakhsh, M., Poursaeedi, A., \& Asadollahi, A. R. (2012). An analysis of factors affecting on online shopping behavior of consumers. International Journal of Marketing Studies, 4(5), 81.

Jiang, L., Yang, Z., \& Jun, M. (2013). Measuring consumer perceptions of online shopping convenience. Journal of Service Management, 24(2), 191214.

Johnson, D. G. (2015). Technology with no human responsibility?. Journal of Business Ethics, 127(4), 707-715. 
Kumar, V., Anand, P., \& Mutha, D. (2016). A study on trust in online shopping in Pune: A comparative study between male and female shoppers. Prerna and Mutha, Devendra, A Study on Trust in Online Shopping in Pune: A Comparative Study between Male and Female Shoppers (February 12, 2016).

Lee, Y. C. (2006). An empirical investigation into factors influencing the adoption of an e-learning system. Online information review, 30(5), 517541.

Li, R., Chung, T. L. D., \& Fiore, A. M. (2017). Factors affecting current users' attitude towards e-auctions in China: An extended TAM study. Journal of Retailing and Consumer Services, 34, 19-29.

Mahadeo, J. D. (2009). Towards an Understanding of the Factors Influencing the Acceptance and Diffusion of e-Government Services. Electronic Journal of E-government, 7(4), 391-402.

Mandhlazi, L., Dhurup, M., \& Mafini, C. (2013). Generation Y consumer shopping styles: evidence from South Africa. Mediterranean Journal of Social Sciences, 4(14), 153.

Ngai, E. W., Poon, J. K. L., \& Chan, Y. H. (2007). Empirical examination of the adoption of WebCT using TAM. Computers \& education, $48(2)$, $250-267$.

Oliveira, T., Alhinho, M., Rita, P., \& Dhillon, G. (2017). Modelling and testing consumer trust dimensions in e-commerce. Computers in Human Behavior, 71, 153-164.

Oliveira, T., Faria, M., Thomas, M. A., \& Popovič, A. (2014). Extending the understanding of mobile banking adoption: When UTAUT meets TTF and ITM. International journal of information management, 34(5), 689-703.

Oni, A. A., \& Ayo, C. K. (2010). An empirical investigation of the level of users' acceptance of e-banking in Nigeria. Journal of Internet Banking and Commerce, 15(1), 1-13.

Pando-Garcia, J., Periañez-Cañadillas, I., \& Charterina, J. (2016). "Business simulation games with and without supervision: An analysis based on the TAM model". Journal of Business Research, 69(5), 1731-1736.

Park, S. Y., Nam, M. W., \& Cha, S. B. (2012). University students' behavioral intention to use mobile learning: Evaluating the technology acceptance model. British Journal of Educational Technology, 43(4), 592-605.

Patel, K. J., \& Patel, H. J. (2018). Adoption of internet banking services in Gujarat. International Journal of Bank Marketing.

Praveena, K., \& Thomas, S. (2014). Continuance intention to use Facebook: A study of perceived enjoyment and TAM. Bonfring International Journal of Industrial Engineering and Management Science, 4(1), 24-29.

Richa, D. (2012). Impact of demographic factors of consumers on online shopping behaviour: A study of consumers in India. International Journal of Engineering and Management Sciences, 3(1), 43-52.

Sánchez-Prieto, J. C., Olmos-Migueláñez, S., \& García-Peñalvo, F. J. (2017). MLearning and pre-service teachers: An assessment of the behavioral intention using an expanded TAM model. Computers in Human Behavior, 72, 644-654.

Singh, N., Yadav, M., \& Sahu, O. (2016). Consumer acceptance of apparel e-commerce-Ethiopia. Intellectual Economics, 10(1), 55-62.

Singh, S., \& Srivastava, P. (2019). Social media for outbound leisure travel: a framework based on technology acceptance model (TAM). Journal of Tourism Futures.

Suh, B., \& Han, I. (2002). Effect of trust on customer acceptance of Internet banking. Electronic Commerce and Applications, 1(3), 247-263.

Suki, N. M., \& Ramayah, T. (2010). User acceptance of the e-government services in Malaysia: structural equation modelling approach. Interdisciplinary Journal of Information, Knowledge and Management, 5, 395-414.

Suleman, D., Zuniarti, I., Setyaningsih, E. D., Yanti, V. A., Susilowati, I. H., Sari, I., ... \& Lestiningsih, A. S. (2019). Decision Model Based on Technology Acceptance Model (Tam) for Online Shop Consumers in Indonesia. Academy of Marketing Studies Journal.

Teo, T. (2010). A path analysis of pre-service teachers' attitudes to computer use: applying and extending the technology acceptance model in an educational context. Interactive Learning Environments, 18(1), 65-79.

Teo, T. (2012). Examining the intention to use technology among pre-service teachers: An integration of the technology acceptance model and theory of planned behavior. Interactive Learning Environments, 20(1), 3-18.

Thong, J. Y., Hong, S. J., \& Tam, K. Y. (2006). The effects of post-adoption beliefs on the expectation-confirmation model for information technology continuance. International Journal of Human-Computer Studies, 64(9), 799-810.

Venkatesh, V., \& Bala, H. (2008). Technology acceptance model 3 and a research agenda on interventions. Decision sciences, 39(2), 273-315. 
Venkatesh, V., Morris, M. G., Davis, G. B., \& Davis, F. D. (2003). User acceptance of information technology: Toward a unified view. MIS quarterly, 425-478.

Venkatesh, V., Thong, J. Y., \& Xu, X. (2012). Consumer acceptance and use of information technology: extending the unified theory of acceptance and use of technology. MIS quarterly, 36(1), 157-178.

Wang, F., \& Head, M. (2007). How can the web help build customer relationships?: an empirical study on e-tailing. Information \& Management, 44(2), 115-129.

Wang, T. L., \& Tseng, Y. F. (2011). A study of the effect on trust and attitude with online shopping. International Journal of Digital Society, 2(2), 433440.

Wang, X., \& Goh, D. H. L. (2017). Video game acceptance: a meta-analysis of the extended technology acceptance model. Cyberpsychology, Behavior, and Social Networking, 20(11), 662-671.

Weng, F., Yang, R. J., Ho, H. J., \& Su, H. M. (2018). A TAM-based study of the attitude towards use intention of multimedia among school teachers. Applied System Innovation, 1(3), 36.

Yoon, C. (2009). The effects of national culture values on consumer acceptance of e-commerce: Online shoppers in China. Information \& Management, 46(5), 294-301. 